\title{
Onde fica o amor?
}

\section{Ana Campos}

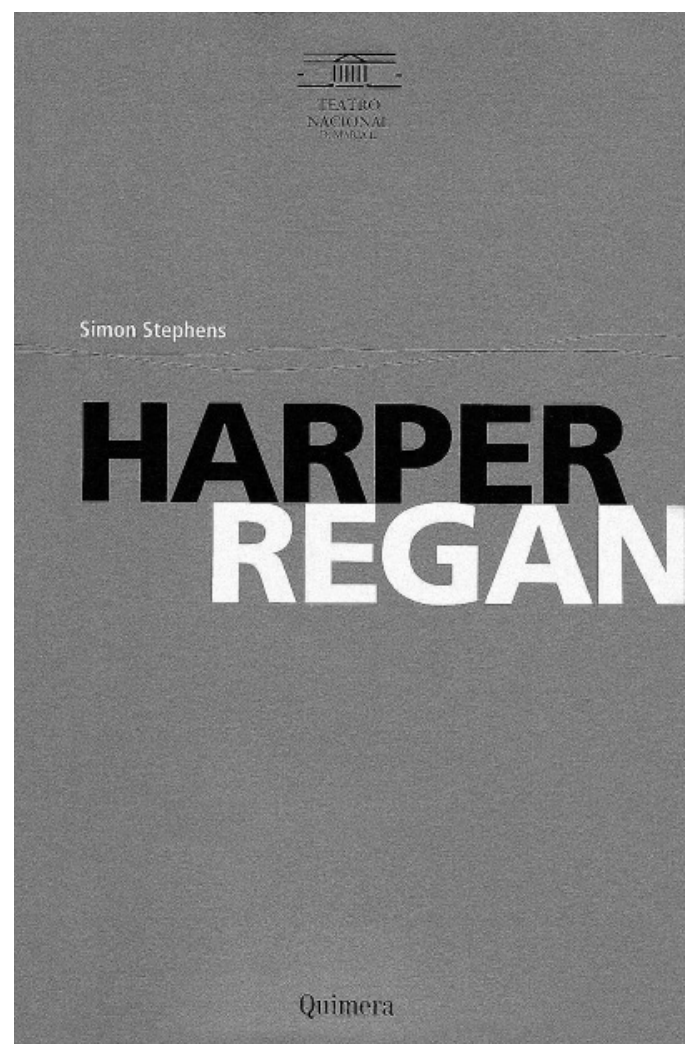

Simon Stephens, Harper Regan, tradução de Jorge Carvalho, Lisboa, Quimera \&t Teatro Nacional D. Maria 11, 2009, 138 pp.

Em 2009, 0 TNDMII iniciou, de forma oportuna e culturalmente inteligente, a edição dos textos levados à cena neste teatro num total, até à data, de cerca de vinte obras de autores nacionais e estrangeiros, de natureza muito diversa, ainda que todos eles lançando novas e antigas interrogações sobre a condição humana e a sua deambulação pelo mistério da vida.

Partindo de Menina Júlia de Strindberg e percorrendo autores tão diversos como Simon Stephens, Tracy Letts, Mick Gordon e Paul Broks, Joan Didion, Abel Neves, David Harrower, Sófocles numa versão de Jorge Silva Melo, Patricia Portela, John Kolvenbach, Alfred de Musset, André Murraças, Bernard Pomerance, Carlos J. Pessoa, Cláudia Lucas Chéu, Dennis Potter, Alain-René Lesage e Arthur Schnitzler, a colecção, editada inicialmente em parceria com a Quimera Editores e depois com a Bicho do Mato, apresenta peças intemporais e outras menos conhecidas do público, numa grande heterogeneidade de temas e de

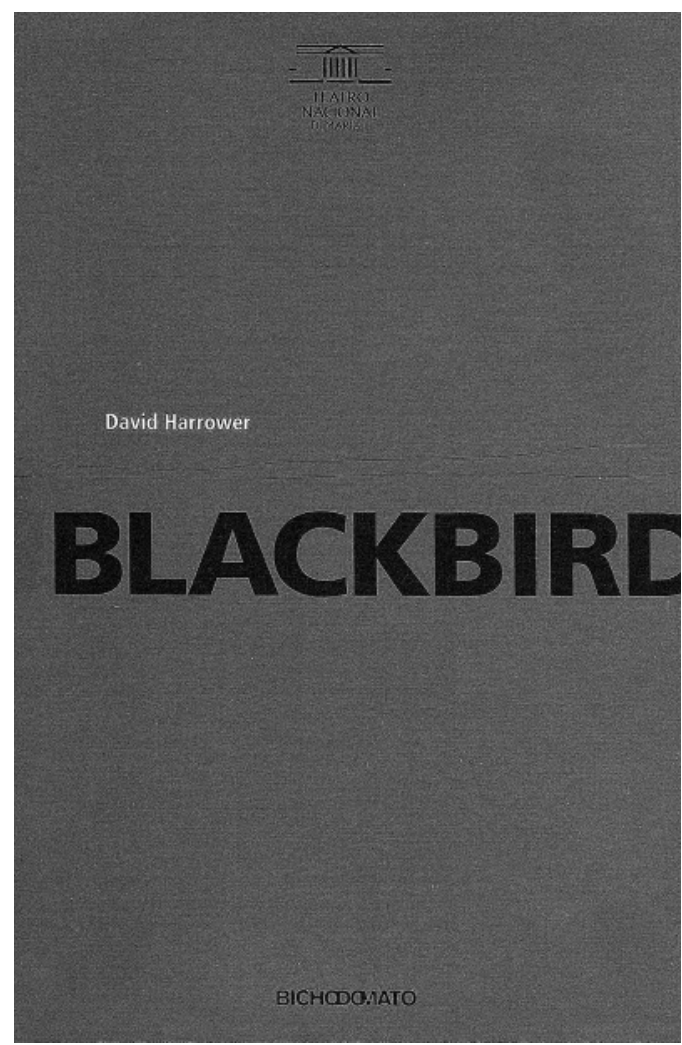

David Harrower, Blackbird, tradução de Tiago Guedes, Lisboa, Lisboa \&t Bicho do Mato, 2010, $107 \mathrm{pp}$.

qualidade dos textos que têm em comum o questionamento do sentido da vida.

Centraremos a nossa análise em dois textos, muito particularmente, em duas figuras femininas que por ai se inventam: Harper Regan, no texto homónimo de Simon Stephens, e Una, em Blackbird, da autoria de David Harrower. Estreada em Portugal na Sala Estúdio do TNDMII a 7 de Maio de 2009, Harper Regan acompanha o percurso da personagem principal durante dois dias e duas noites numa viagem a caminho da sua terra natal para visitar o pai moribundo que viria a falecer antes da sua chegada. Este caminho, ao longo do qual se cruza com outras personagens que a vão gradualmente modificando, é uma viagem em busca de si mesma e também um retrato curioso da Inglaterra actual.

Harper Regan tem quarenta e um anos, uma filha de dezassete, que dela se envergonha, e um marido arquitecto acusado de pedofilia por ter tirado fotos a crianças na rua
Ana Campos é professora do ensino secundário e investigadora do Centro de Estudos de Teatro da Faculdade de Letras da Universidade de Lisboa. 


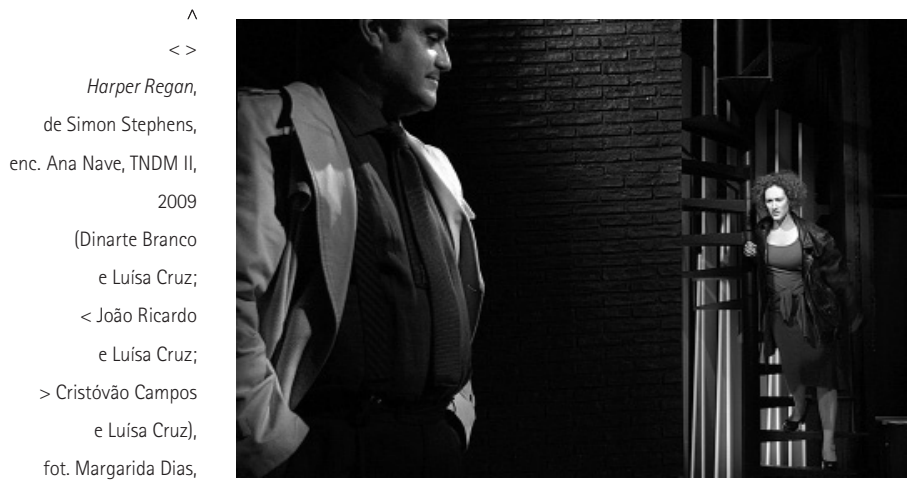

TNDMII.

e as ter colocado na internet e, embora nunca se saiba ao certo se o marido é ou não culpado, a suspeição recai sobre ele irremediavelmente. É, por um lado, o não-amor que caracteriza Harper Regan, e, por outro, é uma vontade imensa de se amar a si mesma - independentemente dos seus papéis sociais de boa mãe, boa esposa, boa profissiona - para depois regressar ao seu lugar de mulher convencional.

As personagens, com quem se cruza, não deixam de fazer críticas acertadas à sociedade em que vivem, revelando, contudo, um comportamento em contradição com o que apregoam. É o caso, por exemplo, do seu patrão, que afirma sem pejo a sua opinião sobre a juventude e,

simultaneamente, se recusa a deixá-la tirar uns dias para visitar o pai que morre.

ELWOOD: Não é imoralidade, Harper. É uma inabilidade total para agi com sentido moral. Uma total ausência disso, em primeiro lugar. É isso que começa a infectar os nossos jovens. Em Inglaterra. (Stephens 2009: 9)

Esta hipocrisia moral, que vai além da própria mentira (pois revela uma total falta de auto-consciência), é também visivel no jornalista viciado em cocaina, que ela encontra num bar e a tenta seduzir, insultando-a ao sentir a sua não correspondência e acabando por ser ferido por ela no pescoço com um copo de vidro.

Nas entrelinhas, lêem-se ainda outras críticas, por exemplo, ao sucessivo despedimento de jornalistas em virtude do crescimento exponencial da internet.

MICKEY: Estão a livrar-se das pessoas da indústria das noticias, em geral. Não os censuro. Pode-se procurar no Google todas as noticias que se quiser. É cortar e colar. Livram-se dos intermediários. (Ibidem: 69)

A presença da internet como grande transformadora dos hábitos das pessoas e das relações sociais é um tema muito actual e perpassa toda a obra. Desde a afirmação
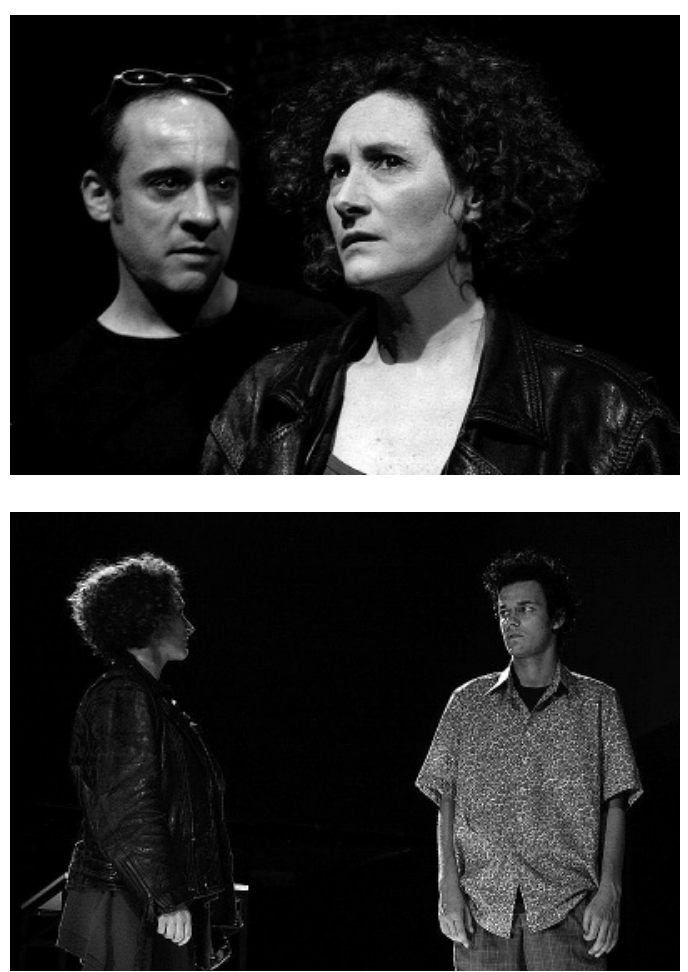

inicial do patrão de Harper, de que faz tudo online, passando pelo jornalista que gosta mais de pornografia no computador do que de sexo, terminando com um encontro para sexo ocasional entre Harper e um homem casado que conheceu nesse dia num chat e a quem se confessa. Esse encontro é, de resto, um momento fundamental, pois ai a protagonista redescobre-se enquanto mulher, afirmando a sua individualidade para além do marido e das imposições sociais.

Outros aspectos a ter em conta são as conflituosas relações familiares num tempo em que as hierarquias dentro dos núcleos familiares estão de algum modo subvertidas. Harper não consegue lidar com a sua própria mãe, tal como a sua filha a não aceita nem compreende.

HARPER: Eu queria ser amada incondicionalmente e tu querias ser mais amada do que qualquer pessoa no mundo. Eu acho que nos decepcionámos mutuamente. E acho que isso acontece sempre. Vejo isso na Sarah. Ela está a fazer comigo exactamente a mesma coisa que eu fiz contigo. É completamente inevitável. É horrivel. Mas nunca pensei que tivesses a lata de me mentir sobre uma coisa como esta (Ibidem: 109)

A peça está repleta de pequenos outros apontamentos que nos apresentam a complexidade da vida na Inglaterra de hoje, como a intolerância para com os judeus ainda visivel nas palavras de Mickey, a incapacidade de inserção social e o isolamento que isso cria em Tobias, a visão extraordinariamente retrógrada que tem sobre o vestuário das pessoas, a opinião do pai que as mulheres devem ficar em casa a cuidar dos filhos, e mesmo a morte solitária dos mais velhos.

A grande ousadia da obra vai contudo para a consciência que cria no leitor de que há vítimas inocentes na actual caça às bruxas relativamente aos pedófilos. A familia de Harper foi minada por esta questão, o seu amor pelo marido desapareceu, e a sua crise pessoal foi por aí 
despoletada. Até ao final nunca sabemos se Seth foi ou não culpado, apesar de ter alegado que sim a fim de poupar a familia ao julgamento.

Num momento em que a emancipação feminina no mundo ocidental parece ser um dado adquirido, Simon Stephen propõe uma mulher na casa dos quarenta, convencional, como tantas e tantas outras, que consegue realizar-se através de sexo ocasional, que se insurge contra o assédio do patrão e sai do escritório sem a sua autorização, capaz de atacar com um copo um homem que a tenta seduzir num bar e a ofende perante a sua recusa. Esta mulher é tão autenticamente real que nos faz questionar se a emancipação feminina conseguiu de facto romper os estereótipos clássicos. Harper Regan é isso tudo, mas é mais. É uma mulher que se procura a si mesma dentro do mundo e das oportunidades que lhe surgem. Quer mais, quer-se a si própria, quer ser ela própria sem constrangimentos para poder voltar a casa e assumir de novo os papéis sociais que a enquadram e lhe dão segurança. Se fosse um homem, esta personagem nada teria de original: o espectador veria nele um cliché, um comportamento habitual e degradante; mas Harper é uma mulher que ousa ir mais longe e voltar, porque o lugar desta e de muitas outras mulheres continua a ser o da desmultiplicação entre a casa, o trabalho, a familia e o seu próprio eu, e é isso mesmo que ainda é esperado delas.

Encontramos na personagem Una, de Blackbird, peça estreada em Portugal na Sala Estúdio do TNDMII a 14 de Janeiro de 2010, a mesma naturalidade na abordagem de temas muito actuais e polémicos como a pedofilia. Una, exLolita de Ray, que se baseia nos crimes do pedófilo Toby Studebaker, procura o homem que abusou dela na adolescência, mas por quem nutriu e nutre, como normalmente acontece nestes contextos, um certo afecto. Adolescente rebelde e mal amada pelos pais, Una apaixonouse por um homem mais velho, com quem teve relações sexuais e que a abandonou à sua sorte quando foi desmascarado, e é esse abandono - e o facto de o ter perdido - que realmente a destrói, bem como a vergonha pública e a culpabilização pela sociedade. Ray pagou com a prisão a sua dívida para com a sociedade, mas não a pagou a Una. Aquela rebeldia adolescente marca-la-á toda a vida e condicionará o seu relacionamento com os homens, no entanto o que mais a preocupa não é o abuso em si, mas a posterior frieza afectiva de Ray. E o espectador é levado a reflectir sobre a real dimensão de casos como este sem a mediação dos meios de comunicação social. Ray não é necessariamente mau, nem Una necessariamente vítima, e esse é o cerne da questão. São duas pessoas que tentam manter a dignidade depois de uma situação, que é mais que nunca condenada violentamente pela sociedade, mas que tem no seu âmago uma ausência desesperada de afectos.

0 espaço e o tempo são elementos fundamentais para conferirem a este texto uma grande força dramática. Uma sala repleta de lixo é a grande metáfora da miséria humana subjacente àquela discussão, e o facto de a acção representar os exactos noventa minutos da conversa entre os dois conferem a este diálogo - feito sobretudo de frases muito curtas - uma extraordinária tensão emocional.

Ela olha para uns restos de lixo espalhados perto da porta.

UNA: As pessoas que só

estão sempre à espera de que alguém limpe por elas.

Uma vez perguntei a um homem

ele deitou ao chão uma lata vazia

uma lata de cerveja

e um pacote de batatas

para o chão.

Deixou cair.

Não pensou no assunto, deixou cair e pronto.

Eu disse-Ihe para ele apanhar aquilo.

Ele riu-se.

Pensou que eu estava a brincar.

Ele estava

RAY: Tu vais

Ele pisca os olhos e depois esfrega-os.

UNA: com uma mulher.

Cabra, chamou-me ela.

Defendeu-o,

E ele a rir-se (Harrower 2010: 15)

Encontramos nesta passagem a síntese da posição de Una. Ela quer confrontar Ray e descobrir exactamente o que se passou entre eles, e essa descoberta é, tanto para ela como para o espectador, muito dolorosa. Ray não voltou a ter comportamentos pedófilos, contudo, no final, ele é surpreendido pela enteada que tem a mesma idade que Una tinha quando foi abusada. Una descobre que o homem, em quem encontrou afecto, não a abandonou propositadamente, mas que foi obrigado a isso ao sentirse perseguido por pedofilia na pequena cidade piscatória onde estavam hospedados. Mais grave é ver que ao afecto, que the devotou e que a impede de ser uma adulta equilibrada, Ray responde com um total desafecto, desculpabiliza-se com os problemas que tinha na altura, protege a sua privacidade e, ao contrário do que acontece com Una, tenta a todo custo recuperar a sua dignidade e viver normalmente.

A escolha destas duas peças para apresentar - e, de algum modo destacar - o valor desta colecção que o TNDMII trouxe ao teatro em Portugal, reside no facto de ambas serem de uma actualidade extrema no modo como questionam temas tão controversos e tão mediatizados de forma politicamente correcta. Ainda que diferentes na atitude perante a vida, estas mulheres são retratos verosimeis do que é viver na sociedade contemporânea onde o discurso socialmente aceite é ainda muitas vezes completamente desfasado da realidade. 